\title{
Measuring air layer volumes retained by submerged floating-ferns Salvinia and biomimetic superhydrophobic surfaces
}

\author{
Matthias J. Mayser ${ }^{*} \neq 1,2$, Holger F. Bohn ${ }^{\ddagger 2,3}$, Meike Reker ${ }^{2}$ \\ and Wilhelm Barthlott ${ }^{2}$
}

\section{Full Research Paper}

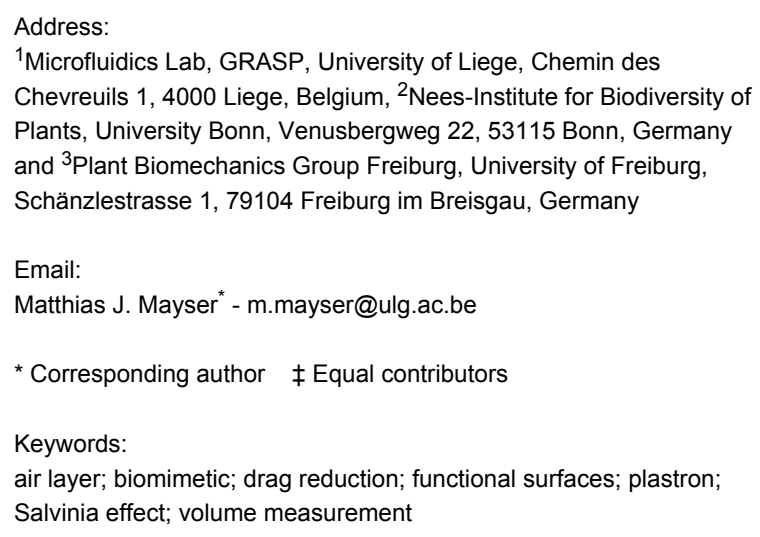

${ }^{1}$ Microfluidics Lab, GRASP, University of Liege, Chemin des Chevreuils 1, 4000 Liege, Belgium, ${ }^{2}$ Nees-Institute for Biodiversity of Plants, University Bonn, Venusbergweg 22, 53115 Bonn, Germany and ${ }^{3}$ Plant Biomechanics Group Freiburg, University of Freiburg, Schänzlestrasse 1, 79104 Freiburg im Breisgau, Germany

Email:

Matthias J. Mayser* - m.mayser@ulg.ac.be

* Corresponding author $\ddagger$ Equal contributors

Keywords:

air layer; biomimetic; drag reduction; functional surfaces; plastron;

Salvinia effect; volume measurement

Beilstein J. Nanotechnol. 2014, 5, 812-821. doi:10.3762/bjnano.5.93

Received: 18 March 2014

Accepted: 07 May 2014

Published: 10 June 2014

Associate Editor: K. Koch

(c) 2014 Mayser et al; licensee Beilstein-Institut. License and terms: see end of document.

\begin{abstract}
Some plants and animals feature superhydrophobic surfaces capable of retaining a layer of air when submerged under water. Longterm air retaining surfaces (Salvinia-effect) are of high interest for biomimetic applications like drag reduction in ship coatings of up to $30 \%$. Here we present a novel method for measuring air volumes and air loss under water. We recorded the buoyancy force of the air layer on leaf surfaces of four different Salvinia species and on one biomimetic surface using a highly sensitive custom made strain gauge force transducer setup. The volume of air held by a surface was quantified by comparing the buoyancy force of the specimen with and then without an air layer. Air volumes retained by the Salvinia-surfaces ranged between 0.15 and $1 \mathrm{~L} / \mathrm{m}^{2}$ depending on differences in surface architecture. We verified the precision of the method by comparing the measured air volumes with theoretical volume calculations and could find a good agreement between both values. In this context we present techniques to calculate air volumes on surfaces with complex microstructures. The introduced method also allows to measure decrease or increase of air layers with high accuracy in real-time to understand dynamic processes.
\end{abstract}

\section{Introduction}

Since the description of hierarchically structured, superhydrophobic, self-cleaning plant surfaces (Lotus-effect) [1,2] there has been an increasing interest in superhydrophobic surfaces [3-5]. Superhydrophobicity describes the extreme repellence of water by a surface. The level of water repellence is usually described by the contact angle which is the angle between the solid and the liquid at the three-phase contact line. Contact angles above $90^{\circ}$ are considered hydrophobic while surfaces 
with contact angles above $150^{\circ}$ are called superhydrophobic [6-9]. Smooth surfaces can reach a maximum contact angle of $120^{\circ}[10]$. Accordingly superhydrophobicity can only be achieved by a combination of a hydrophobic surface chemistry and surface structures on the micro and nano scale [11]. On these structured surfaces superhydrophobicity can occur either in the fully wetted state as described by Wenzel [12] or in the form of water sitting only on the tips of the surface structures (Cassie-Baxter wetting state) [13]. The contact angle of water droplets can be equally high in both wetting states [14,15]. However, in the Wenzel wetting state the water is in full contact with the surface and individual droplets adhere firmly [16]. In contrast to this in the Cassie wetting state the solid-water interface is strongly reduced while the majority of the interface is between water and air, thereby trapping an air layer between water and surface. As a result the adhesion of the water to the surface is minimised and individual droplets often roll off at very low tilting angles. However for true and persisting superhydrophobicity the Cassie wetting state has to be stable, i.e., no wetting transitions should occur [17,18]. One effective solution to prevent wetting transitions are surfaces with multiscale roughness [19-21]. Recently potential applications for these trapped air layers in the Cassie wetting regime have been proposed which include drag reducing ship coatings or fluid channels [22-26] with the capability of 30\% drag reduction [27] and could provide high economic and ecologic value $[28,29]$.

While superhydrophobic plant surfaces, e.g., the leaves of Lotus (Nelumbo nucifera) provide very high contact angles and low hysteresis [1], the air layers that are held between the surface structures persist only for short periods of time [22]. However, for some biological surfaces like the elytra of the back swimmer Notonecta or the upper leaf side of floating ferns of the genus Salvinia air layers are reported to persist from several days up to months [30-32]. Responsible for the long-term air retention in these organisms is a dense cover of elaborate, hydrophobic hairs on their surfaces (Figure 1). In Salvinia these hairs possess a multiscale roughness on several hierarchical levels resulting in a stable Cassie wetting state [17].

In the floating fern genus Salvinia four different shapes of such hairs (trichomes) have been described [33]. In the simplest case these are individual multicellular, uniseriate trichomes. In the most complex case four multicellular, uniseriate trichomes are grouped on top of an emergence and join at their tips forming a so called "egg beater" hair. These hairs with heights between approximately 300 and $2200 \mu \mathrm{m}$ cover the major part of the upper leaf side (Figure 1). Towards the margin of the leaf the height of the hairs decreases gradually in a smooth transition (Figure 1) [33]. This 'edge effect' is probably responsible to maintain an entire air layer over the leaf. Both the hairs and the remaining cell surface are hydrophobically covered with waxes in the shape of thin rodlets perpendicular to the surface [33-35]. As special characteristic of $S$. molesta the topmost cells of its hairs lack the wax cover and are thereby hydrophilic while the remaining part is hydrophobic. The resulting pinning of the water to these hydrophilic tips 'Salvinia-effect' has been proven to increase the stability of the air layer under low pressure conditions (e.g., turbulences) and prevent the extraction of air large bubbles [35,36].

Though the air layers held by Salvinia leaves have previously been studied qualitatively, the amount of air, held in these layers, has not been quantified. In this study we present a new method to measure the volume of air retained by biological and artificial superhydrophobic surfaces quantitatively. Air layers of four Salvinia species and of well defined replicas were analysed.

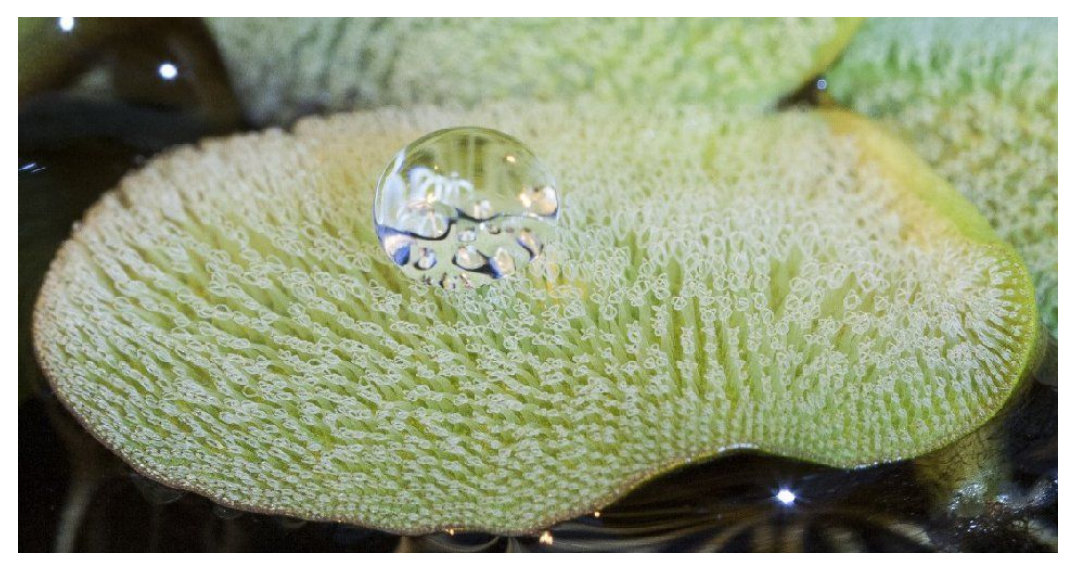

Figure 1: Leaf of Salvinia molesta floating on water. The leaf surface is densely covered with complex superhydrophobic "egg-beater" hairs. The height of the hairs decreases towards the margin of the leaf. An applied water droplet resides on the tips of the hairs without sinking between the hairs. 


\section{Results and Discussion Air volume on wafer replica}

For the validation of the method we use the microstructured wafer replicas as a defined control surface and compare the measured values with the calculated theoretical air volumes.

The theoretical air volume held by the wafer is determined by the dimension of the microstructured area subtracted by the volume occupied by the pillars. Thus the proportion of air per total surface area $\left(i_{\mathrm{A}}\right)$ is

$$
i_{\mathrm{A}}=1-2 \pi\left(\frac{r}{a}\right)^{2}=0.956
$$

with $r$ being the pillar radius and $a$ the diagonal pitch of the pillars.

The structured area has a length $l$ of $18.8 \mathrm{~mm}$, a width $w$ of $14 \mathrm{~mm}$ and $60 \mu \mathrm{m}$ pillar height $h$. Assuming a smooth air-water interface the theoretical air volume $V_{\mathrm{A}}$ can be calculated to

$$
V_{\mathrm{A}}=l \cdot w \cdot h \cdot i_{\mathrm{A}}=15.1 \mathrm{~mm}^{3}
$$

The air volume held by the microstructured wafer replicas was measured to a mean value of $14.8 \pm 0.3 \mu \mathrm{L}(n=10)$. This is approximately $2 \%$ below the theoretical air volume, which also lies within the standard deviation of the measured data. The slightly lower values might be explained by the shape of the air water interface, which is not smooth but sagging in between the pillars, so that the real air volume should be slightly smaller than the theoretical value [37]. Another reason could be defects in the hydrophobic coating, leading to small areas, where there might have happened a transition to the Wenzel wetting state thereby reducing the air volume of the sample. In two cases the measured values were higher than the calculated one. These higher air volumes were probably caused by small air pockets on top of the structured surface or bubbles below the sample, which could appear if the replica was submerged to fast.

\section{Air volumes on Salvinia leaves}

The air volumes held by four different Salvinia species were more variable due to the more complex surface microstructure (see Figure 4) and great differences in leaf surface area which ranged from $44 \pm 8 \mathrm{~mm}^{2}$ for $S$. minima up to $1388 \pm 149 \mathrm{~mm}^{2}$ for S. oblongifolia (S. cucullata: $224 \pm 23 \mathrm{~mm}^{2}, S$. molesta $359 \pm 52 \mathrm{~mm}^{2}$ ). For better comparability of the different species we normalised the measured air volumes with the leaf surface area (Figure 2). In order to test whether the leaf surface area has an influence on the air volume per surface area we performed a linear correlation analysis. For the species with small leaves, S. minima $\left(r^{2}=0.665, p \leq 0.05\right)$ and $S$. cucullata $\left(r^{2}=0.273\right.$, $p \leq 0.05)$ a significant correlation was found. In the species with larger leaves, $S$. molesta $\left(r^{2}=0, p=0.992\right)$ and $S$. oblongifolia $\left(r^{2}=0, p=0.971\right)$ an effect of the overall leaf surface area on
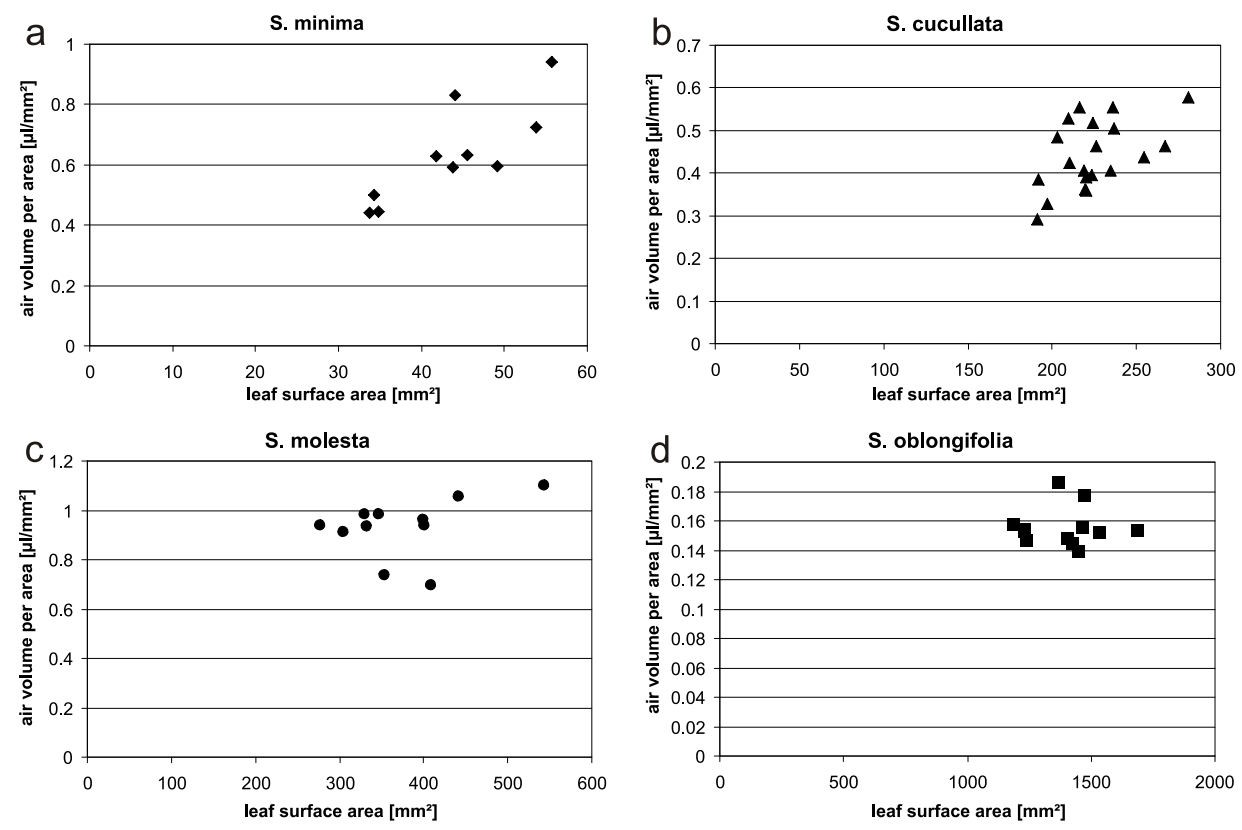

Figure 2: Air volume per surface area measured on four different Salvinia species. a) S. minima $(n=10)$, b) $S$. cucullata $(n=19)$, c) $S$. molesta $(n=11)$, d) S. oblongifolia $(n=12)$ 
the air volume per surface area could not be found. As the trichomes decrease in height towards the leaf edges, the air volume per leaf area also decreases towards the leaf edges. Idealising a leaf as a circle, the edge length (circumference) rises linearly with radius $(C=2 \pi r)$ while there is a quadratic increase for the leaf surface area $\left(A=\pi r^{2}\right)$. Accordingly the decreasing air volumes towards the edges of the leaves have a larger influence on the overall air volume on small leaves of S. minima and $S$. cucullata (Figure 2a,b), than they have in species with larger leaves like S. molesta and S. oblongifolia (Figure 2d).

For the theoretical volume calculation we assume a circular leaf (radius $R$ ) with a linear decline of the trichome height $H$ towards the edge for a width $W$ specified for each species (see Table 1). This results in an air layer in the shape of a truncated cone. The volume of this truncated cone represents the maximum theoretical volume $V_{\max }$ of an air layer on a leaf with a given surface area and can be calculated to

$$
V_{\max }=\pi \cdot H \cdot\left[R \cdot(R-W)+1 / 3(W)^{2}\right]
$$

Divided by the overall surface area, this results in the mean air height. For an infinitely large leaf, where the decrease of trichome height at the edge is negligible, this should almost equal the trichome height on the plants.

Comparing the theoretical values with the values measured on Salvinia leaves shows different results for the different species (Figure 3). All measured values are below the calculated theoretical ones. Most of these differences can be explained by the volume occupied by the trichomes themselves and by the sagging of the air water interface between the hairs. Since the surface microstructure of the Salvinia leaves is less well defined than in the wafer replicas, these volumes are difficult to measure but can be approximated. Table 1 displays the measured surface structure dimensions and parameters for the four investigated Salvinia species needed for this calculation. To estimate the volume occupied by the trichomes, we idealized them as assemblies of truncated cones for the emergence and the hairs. The volumes of these truncated cones were calculated with the measured mean dimensions (see Table 1), summed up to represent an individual trichome and multiplied by the trichome density $\rho$ to get a volume per surface area (Table 2).

Additionally, to estimate the volume of the water sagging in between the hairs the shape of the air-water interface is transferred to a solid material by a replication technique (see 'Characterisation of the air-water interface'). On these replicas the depth and width of the sagging was measured (Table 2). The indentions of the replicated air-water interfaces were approximated as ball scrapers with the measured width $d$ and height $h$. Their volume $V_{\mathrm{BS}}$ was calculated as

$$
V_{\mathrm{BS}}=\frac{\pi h^{2}}{3}\left(\frac{3}{2} d-h\right)
$$

and then again multiplied with the trichome density $\rho$ to get a volume per surface area (Table 3 ).

When both values are added to the measured air volumes per surface area the results coincide well with the theoretical volumes except for S. molesta (grey symbols in Figure 3). For the other three species the new values are all slightly above the measured air volumes (Table 4). This is due to the hairs bending

\begin{tabular}{|c|c|c|c|c|c|c|}
\hline & & & S. oblongifolia & S. cucullata & S. minima & S. molesta \\
\hline Trichome density & $\rho$ & $1 / \mathrm{mm}^{2}$ & $25.8 \pm 3.3$ & $13.0 \pm 2.6$ & $2.25 \pm 0.23$ & $1.64 \pm 0.24$ \\
\hline Trichome height & $H$ & $\mu \mathrm{m}$ & $310 \pm 41$ & $558 \pm 143$ & $919 \pm 107$ & $2.629 \pm 285$ \\
\hline Trichome length & $L$ & $\mu \mathrm{m}$ & $370 \pm 46$ & $609 \pm 152$ & $995 \pm 108$ & $2.922 \pm 264$ \\
\hline Emergence length & $I_{E}$ & $\mu \mathrm{m}$ & $177 \pm 30$ & n.a. & $443 \pm 93$ & $1.955 \pm 302$ \\
\hline Egg beater shape length & $I_{C}$ & $\mu \mathrm{m}$ & n.a. & n.a. & n.a. & $967 \pm 51$ \\
\hline Hair length & $I_{\mathrm{H}}$ & $\mu \mathrm{m}$ & $222 \pm 28$ & $609 \pm 152$ & $562 \pm 46$ & $1160 \pm 88$ \\
\hline Emergence diameter (base) & $d_{\mathrm{Eb}}$ & $\mu \mathrm{m}$ & $269.0 \pm 8.6$ & n.a. & $287 \pm 18$ & $590 \pm 45$ \\
\hline Emergence diameter (tip) & $d_{\mathrm{Et}}$ & $\mu \mathrm{m}$ & $168 \pm 13$ & n.a. & $139 \pm 11$ & $177 \pm 13$ \\
\hline Egg beater hair diameter & $d_{C}$ & $\mu \mathrm{m}$ & n.a. & n.a. & n.a. & $613 \pm 73$ \\
\hline Hair diameter (base) & $d_{\mathrm{Hb}}$ & $\mu \mathrm{m}$ & $68.5 \pm 6.8$ & $40.5 \pm 6.2$ & $71.2 \pm 6.9$ & $70.9 \pm 6.7$ \\
\hline Hair diameter (tip) & $d_{\mathrm{Ht}}$ & $\mu \mathrm{m}$ & $26.5 \pm 4.8$ & $9.6 \pm 1.3$ & $20.9 \pm 3.0$ & n.a. \\
\hline Width of leaf edge & $w$ & $\mu \mathrm{m}$ & $428 \pm 80$ & $1639 \pm 205$ & $966 \pm 143$ & $3292 \pm 321$ \\
\hline
\end{tabular}
towards the leaf surface when submerged because of the static 


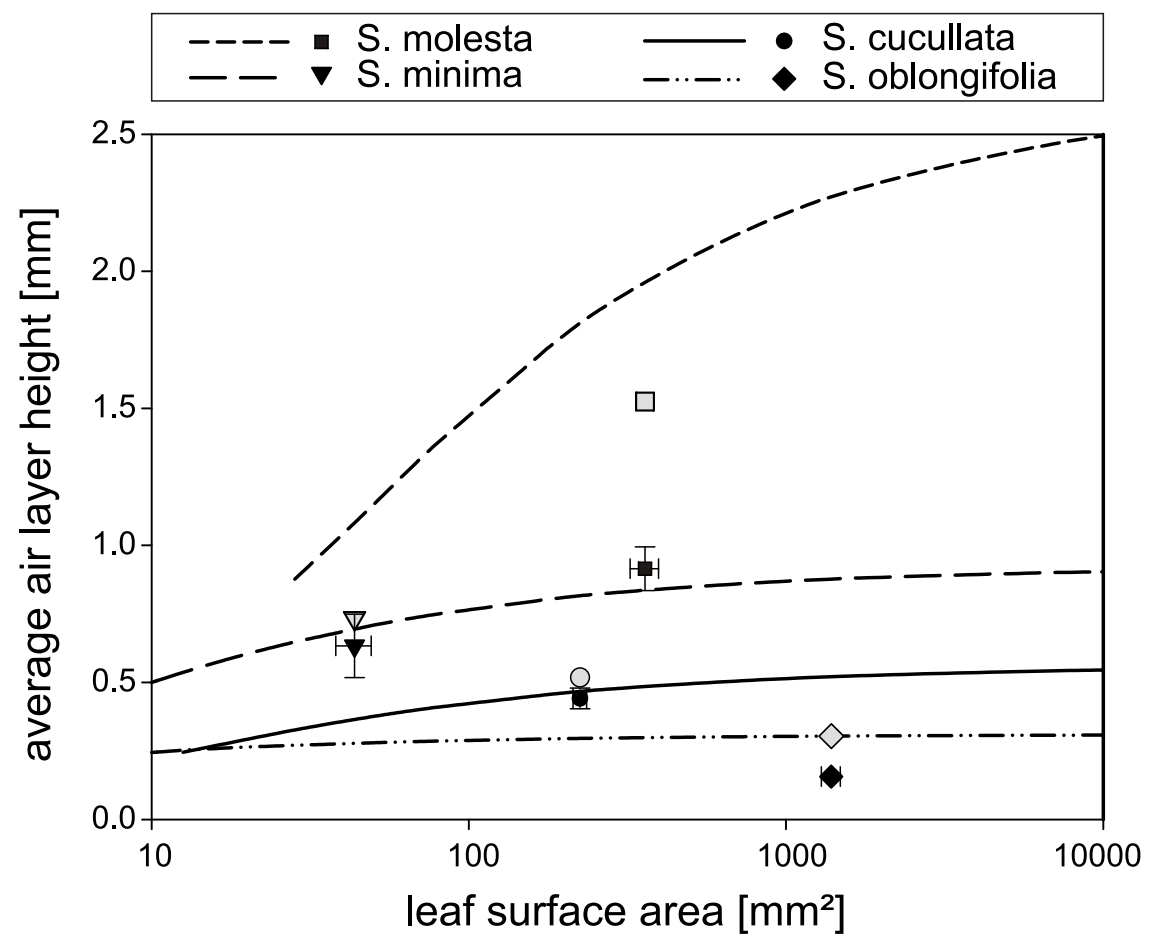

Figure 3: Air volume per surface area measured on four different Salvinia species compared to the calculated theoretically maximum values. (symbols: median values, whiskers: $95 \%$ confidence interval, grey symbols: measured values with calculated values for hair volume and air-water interface sagging added, lines: theoretically maximum values).

Table 2: Calculated trichome volumes.

S. oblongifolia

$\mathrm{nL}$

$\mathrm{nL}$

$\mathrm{nL}$

Volume (emergence)

Volume (trichome)

$\mathrm{nL} / \mathrm{mm}^{2}$

$2 \times 0.42$

4.80

5.64

Trichome volume per surface area

\begin{tabular}{|c|c|}
\hline & $2 \times 0.42$ \\
\hline & 4.80 \\
\hline & 5.64 \\
\hline$/ \mathrm{mm}^{2}$ & 145 \\
\hline
\end{tabular}

S. cucullata

S. minima

S. molesta

$\begin{array}{ccc}0.34 & 4 \times 1.03 & 4 \times 2.08 \\ \text { n.a. } & 16.40 & 241.23 \\ 0.34 & 20.52 & 249.57 \\ 4 & 46 & 409\end{array}$

Table 3: Measurement values and volume calculations of the water sagging in between the hairs (mean \pm s.d., $n=10$ ).

\begin{tabular}{|c|c|c|c|c|c|c|}
\hline & & & S. oblongifolia & S. cucullata & S. minima & S. molesta \\
\hline Width of sagging & $d$ & $\mu \mathrm{m}$ & $193 \pm 36$ & $511 \pm 159$ & $727 \pm 245$ & $1224 \pm 148$ \\
\hline Height of sagging & $h$ & $\mu \mathrm{m}$ & $20.7 \pm 9.2$ & $75.0 \pm 18.4$ & $72.5 \pm 17.3$ & $187.0 \pm 60.8$ \\
\hline Volume of ball scraper & $V_{\mathrm{BS}}$ & $\mathrm{nL}$ & 0.3 & 7.0 & 14.4 & 99.7 \\
\hline Volume of sagging per surface area & & $\mathrm{nL} / \mathrm{mm}^{2}$ & 7.5 & 91.0 & 32.4 & 163.5 \\
\hline
\end{tabular}

Table 4: Difference between the measured air volumes and the calculated theoretically maximum values in percent with and without the hair volumes and the shape of the air-water interface taken into account.

\section{$\begin{array}{llll}\text { S. oblongifolia } & \text { S. cucullata } & \text { S. minima } & \text { S. molesta }\end{array}$}

$\begin{array}{lllll}\text { Difference without hair volume and air-water interface influence } & \% & -48.7 & -5.4 & -10.5 \\ \text { Difference with hair volume and air-water interface influence } & \% & +4.3 & +7.1 & +3.8\end{array}$


water pressure thereby decreasing the volume of the trapped air. During the size measurements the hairs were fully erect, which results in a higher air volume in the calculations. However, for the low submerging depth used in the experiments these differences are very small (Table 4).

S. molesta leaves feature a different leaf form, which consist of two halves joined only in a small portion in the middle and having a rather pointed angle between them. Though the experiments were performed with care to prise the two halves apart, in a portion of the leaf surface near the joint the hair tips would interlink between each other and form an air pocket, which is considerably smaller than an air film with full height on those surfaces. Still the correction of the measured volumes with the hair volumes and air-water interface shape influence reduced the difference between this value and the theoretically calculated one by more than the factor of two (Table 4).

\section{Conclusion}

We have presented a reliable method for precisely measuring volumes of air layers on submerged superhydrophobic surfaces. With the current set-up air volumes up to $900 \mu \mathrm{L}$ can be measured with a precision of $0.1 \mu \mathrm{L}$. By adjusting the lever length of the needle the measurement range and resolution can be tuned appropriate to the sample and air layer volume. Apart from technical surfaces the method has been successfully applied to measure air volumes held by living biological samples. It was shown that the investigated Salvinia species with their highly complex hierarchically structured surfaces hold up to $1 \mathrm{~L} / \mathrm{m}^{2}$ air under water.

Furthermore we demonstrated a method for taking measures of the air-water interface by replicating its shape into a solid material. This in combination with the calculation of the volume of the surface structures allowed us to correlate the measured air volumes with theoretically estimations. The combination of these two techniques allows the precise measurement of air layer heights even if the dimensions of the surface structures are not predefined like on artificial surfaces.

We recently used the method to analyse the long term behaviour of air layers, as it is capable of measuring changes in buoyancy in real-time over extended periods, thereby giving an insight in the dynamic persistence of air layers and the progresses of their decrease (publication in preparation). This knowledge about the dynamic behaviour of air layers can be fundamental for the creation of artificial surfaces with longterm air retention. Recent measurements by our project partners have revealed a drag reduction of $30 \%$ by such air retaining surfaces [27]. Applied on ships this would have a large impact on fuel consumption.

\section{Experimental}

\section{Materials}

In order to test the method with a well-defined, structured surface, a silicon waver $(18.8 \times 14 \mathrm{~mm})$ with pillars of $60 \mu \mathrm{m}$ height, $10 \mu \mathrm{m}$ diameter and a rectangular pattern with $60 \mu \mathrm{m}$ diagonal pitch (Figure 4a) were replicated with epoxy resin (Injection Resin EP, Reckli GmbH, Germany) as described by Koch et al. [38]. Replicas were hydrophobically coated with $25 \mu \mathrm{L}$ of diluted (1:10) Tegotop 210 (Evonik Degussa GmbH, Germany) (Figure 4b).

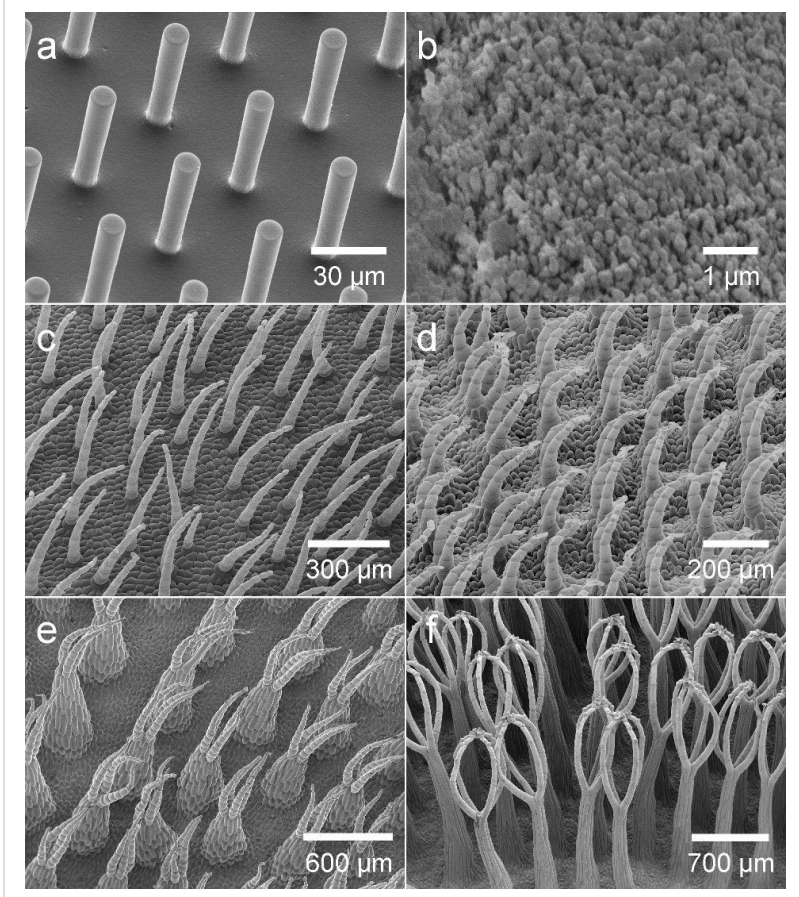

Figure 4: SEM images of technical and biological microstructured surfaces used for air volume measurements. a) uncoated epoxy-resin replica of a silicon wafer with pillars of $10 \mu \mathrm{m}$ diameter and 60 diagonal pitch, b) hydrophobic coating of the replicas with Tegotop 210 in high magnification, $c-f$ ) upper leaf surface of four Salvinia species c) Salvinia cucullata, d) S. oblongifolia, e) S. minima, f) S. molesta.

Fresh leaves of four different Salvinia species representing all described trichome types [33] were measured. S. cucullata (BG BONN 18268) displays simple, slightly curved hairs, consisting of 6 to 8 cells in a row (Figure 4c). S. oblongifolia (BG BONN 14457) incorporates trichomes which consist of two hairs, which grow out of a slight emergence and are joined at their topmost cells (Figure 4d). The Natans-type represented by S. minima (BG BONN 8595) shows four hairs growing on top of a large emergence which are not joined at their tips (Figure 4e). The so called "egg beater" hairs on S. molesta (BG BONN 14459) consist of a large emergence topped with four hairs which are joined at their tips (Figure 4f). Plants were cultivated in the Botanical Gardens of the University of Bonn. 


\section{Buoyancy measurement}

The volume of air retained by a surface was determined by measuring the buoyancy force the air generates. This was accomplished by installing a force transducer consisting of a silicon bending beam with integrated strain gauge (Sensor Element AE801, HJK, Germany) right above the water level in an aquarium filled with water. A metal needle (40 mm length, $0.4 \mathrm{~mm}$ diameter, V2A steel) was bent into an L-shape and glued to the end of the beam with resin glue resulting in the tip of the needle being submerged $20 \mathrm{~mm}$ below the water surface. All specimens were mounted to the force sensor by hanging them into a bend close to the tip of the needle with nylon strings, thereby ensuring a fixed lever arm between the applied weight and the strain gauge (Figure 5a). The change in resistance generated through the bending of the beam by buoyancy forces of the attached specimen was measured by means of a Wheatstone bridge, an amplifier (G1T8, ME Meßsysteme GmbH, Germany) and a A/D converter (NI-USB6009, National Instruments, USA). The recorded voltages were converted into forces through a calibration coefficient acquired with a set of nine weights in the range from 1 to $700 \mathrm{mg}$. The calibration measurements were performed in air prior to the experiment. The calculated coefficient was $45.25 \mathrm{mg} / \mathrm{V}$ with a highly linear behaviour across the whole measurement range (Figure 5b). The buoyancy force of air under water equals the weight difference to the displaced water; accordingly $45.25 \mathrm{mg} / \mathrm{V}$ equals $45.25 \mu \mathrm{L}$ of submerged air per Volt assuming a water density of $1 \mathrm{mg} / \mu \mathrm{L}$. The maximum sensitivity of the measurement was $0.09 \mu \mathrm{L}$.

For proper mounting to the force sensor specimens had to possess negative buoyancy when submerged under water. Thus, Salvinia leaves along with additional weights were glued onto a rectangular plastic straps using a polyvinylsiloxane (President Light Body, ISO 4823, Coltene Whaledent, Hamburg, Germany). Wafer replicas showed negative buoyancy without further modification. Wafers and mounted leaves were attached to two slings of nylon string ( $0.1 \mathrm{~mm}$ diameter), with which they were then hung into the bend of the needle. The samples were thereby held at approximately $80 \mathrm{~mm}$ below the water surface during the experiment. For the measurement a sample with an air layer was attached to the needle and given 10 seconds to stabilise before the buoyancy was recorded (mean value over 10 seconds after stabilising time). Then the sample was detached from the needle, taken out of the water and covered with $70 \%$ ethanol for wetting the surface. Afterwards it was washed for 20 seconds with water and then reattached to the needle for renewed buoyancy measurement. From the difference in buoyancy before and after removal of the air layer its volume was calculated.
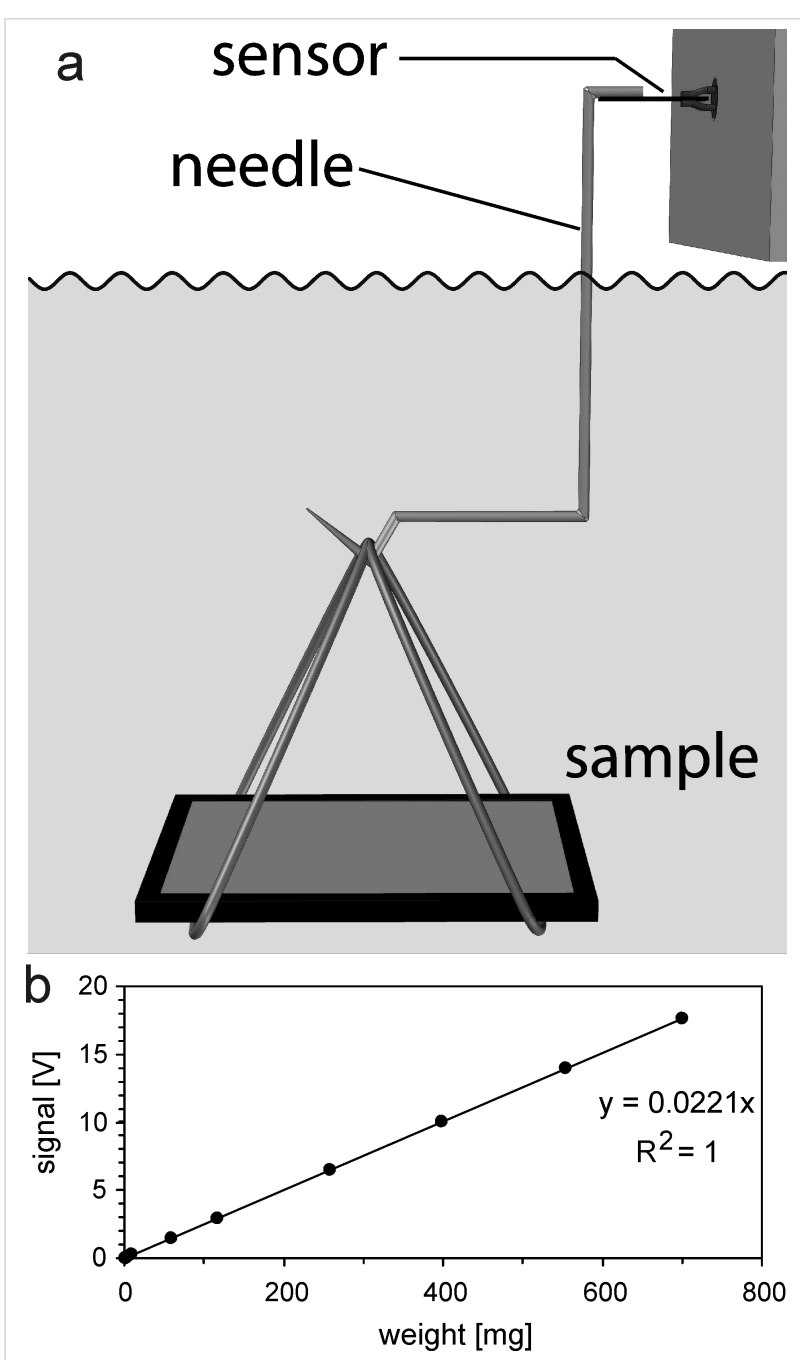

Figure 5: Buoyancy measurement setup. a) Schematic drawing of the measurement setup. A bent metal needle is glued to a silicon strain gauge sensor and submerged under water. Specimens with air layer were hung onto the needle by nylon strings. b) Calibration curve of the force transducer using nine weights in the range between 1 and $700 \mathrm{mg}$.

\section{Surface characteristics of Salvinia and replicas}

The surface microstructures of both technical and biological surfaces were visualised by scanning electron microscopy (SEM). The wafer replicas were coated with gold by a sputter coater (SCD-040, Balzers Union, Liechtenstein) at $60 \mathrm{~mA}$ for 30 seconds before SEM investigation. The plant leaves were prepared for SEM examination by dehydration in alcohol and 'critical point drying' (CPD 020, Balzers Union, Liechtenstein) and also gold coated at $15 \mathrm{~mA}$ for 120 seconds. Electron microscopy was performed on a Cambridge Stereoscan 200 SEM (Zeiss GmbH, Oberkochen, Germany) with digital image processing unit (DISS 5, Point electronic GmbH, Halle, Germany) at acceleration voltages of $15 \mathrm{kV}$ for the replicas and $10 \mathrm{kV}$ for the plant material. 
The leaf surface area was acquired after the volume measurement by scanning the flattened leaf with a flat bed scanner (Canon 4200F, Canon Inc., Japan) and measuring the leaf area on the image according to a calibration grid.

A digital light microscope (VHX-1000, Keyence, Japan) was used to measure the trichome dimensions of the examined Salvinia species. Images of fresh leaves were taken from straight above and sideward in order to measure width and diameter of the trichomes as well as the trichome density (Figure 6). All parameters were taken at the centre of leaf halves (where the hairs are highest) and are given as mean values with standard deviations of $n=10$.

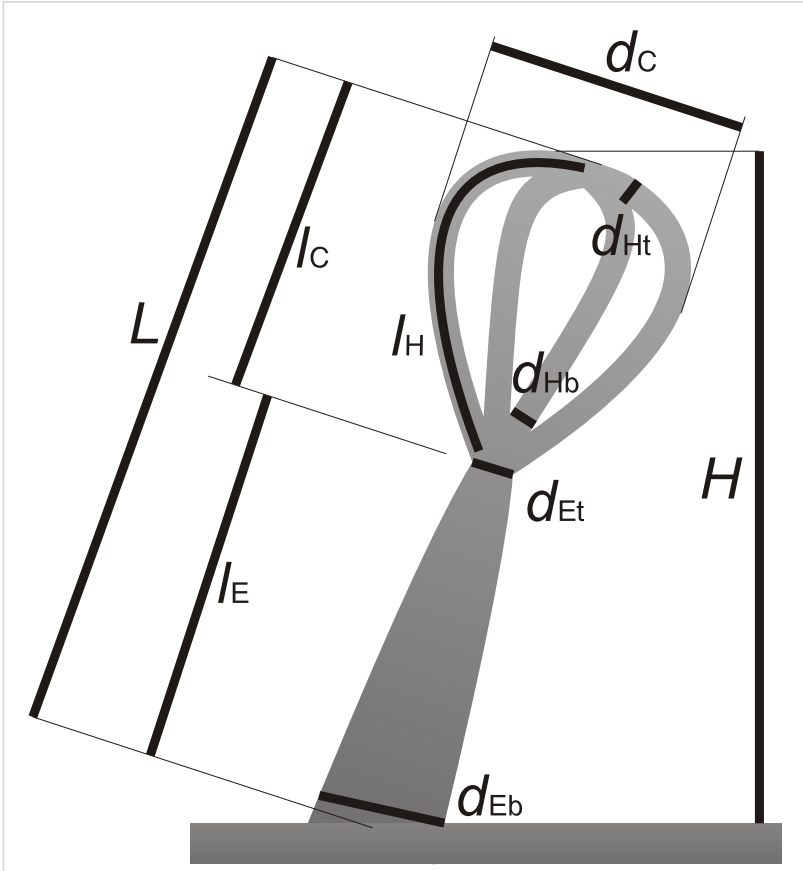

Figure 6: Schematic drawing showing the structural parameters acquired from microscopic images of Salvinia leaf surfaces: trichome height $H$, trichome length $L$, emergence length $I_{E}$, egg beater shape length $I_{\mathrm{C}}$, hair length $I_{\mathrm{H}}$, emergence base diameter $d_{\mathrm{Eb}}$, emergence tip diameter $d_{\mathrm{Et}}$, egg beater shape diameter $d_{\mathrm{C}}$, hair base diameter $d_{\mathrm{Hb}}$, hair tip diameter $d_{\mathrm{Ht}}$.

\section{Characterisation of the air-water interface}

The air-water interface on the Salvinia leaves was replicated into a solid material to be able to measure it and estimate the volume of air displaced by the water sagging in between the hairs. For this purpose individual leaves were attached to the inside of the lid of a standard Petri dish using super glue. The bottom part of the Petri dish was filled with water and afterwards the lid with the attached leaf was placed on top, resulting in the leaf surface just penetrating the water surface inside the Petri dish. The leaf edge was kept out of the water to establish a connection between the air layer and the surrounding air. This prevented the air layer to reduce in volume during cooling, which would have changed the shape of the air-water interface. The assembly was then cooled to $-32{ }^{\circ} \mathrm{C}$. The Petri dish with the frozen water was placed in a box with solid $\mathrm{CO}_{2}$ and the leaf was pulled out of the ice by lifting the lid of the Petri dish. The solid $\mathrm{CO}_{2}$ would serve a dual purpose of maintaining cold temperatures and providing a $\mathrm{CO}_{2}$ atmosphere to prevent humidity from condensing on the frozen air-water interface. The indention in the ice was filled with silicone (Honigum ${ }^{\circledR}$, DMG Chemisch-Pharmazeutische Fabrik GmbH, Hamburg, Deutschland, ISO 4823:2000, Type 3: Light-bodied consistency) which was cooled below $0{ }^{\circ} \mathrm{C}$ previously. The $\mathrm{CO}_{2}$ prevented crystallisation of humidity on the cool surface. After hardening at $-32{ }^{\circ} \mathrm{C}$ for 2 days the silicone was removed from the ice and represented the shape of the air-water interface of the air layer under water (Figure 7). This silicone replica was examined by an optical 3D microscope (Modell VHX-1000, Keyence Corporation, Osaka, Japan) and the depth and width of the sagging was measured.

\section{a}

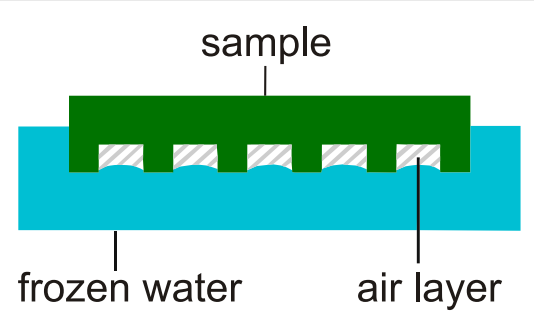

b

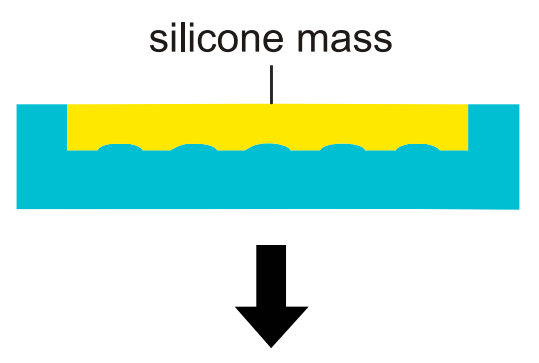

C

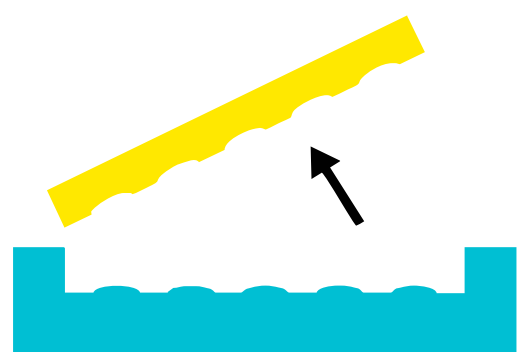

Figure 7: Scheme of the replication of the air-water interface. a) A Salvinia leaf is placed upside down on water and the assembly is cooled to $-32{ }^{\circ} \mathrm{C}$ afterwards. b) After removing the leaf specimen the imprint in the frozen water was filled with cooled silicone. c) After two days the polymerized silicone was removed. 


\section{Acknowledgement}

This work was funded as part of the joint research project 'Luft haltende Schiffsbeschichtungen nach biologischem Vorbild zur Reibungsreduktion' (grant 01RB0803A) by the BIONA program of the Federal Ministry for Education and Research (BMBF) and the Graduiertenkolleg GRK1572 of the Deutsche Forschungsgesellschaft (DFG) as well as the long-term project 'Biodiversity in change' of the Academy of Sciences and Literature in Mainz. The authors thank the Botanical Gardens of the University Bonn for the cultivation and kind provision of the Salvinia plants. We acknowledge our partners, the working group of Professor Alfred Leder (Chair of Fluid Mechanics LSM) at the University of Rostock and the working group of Professor Thomas Schimmel (Institute of Nanotechnology INT) at the Karlsruhe Institute of Technology (KIT) for their cooperation.

\section{References}

1. Barthlott, W.; Neinhuis, C. Planta 1997, 202, 1-8. doi:10.1007/s004250050096

2. Barthlott, W.; Ehler, N. Trop. Subtrop. Pflanzenwelt 1977, 19, 367-467.

3. Gao, L.; McCarthy, T. J. Langmuir 2007, 23, 3762-3765. doi:10.1021/la062634a

4. Gao, L.; McCarthy, T. J.; Zhang, X. Langmuir 2009, 25, 14100-14104. doi:10.1021/la903043a

5. Yan, Y. Y.; Gao, N.; Barthlott, W. Adv. Colloid Interface Sci. 2011, 169, 80-105. doi:10.1016/j.cis.2011.08.005

6. Bhushan, B.; Nosonovsky, M.; Chae Jung, Y. J. R. Soc., Interface 2007, 4, 643-648. doi:10.1098/rsif.2006.0211

7. Jung, Y. C.; Bhushan, B. Nanotechnology 2006, 17, 4970-4980. doi:10.1088/0957-4484/17/19/033

8. Koch, K.; Bhushan, B.; Barthlott, W. Soft Matter 2008, 4, 1943-1963. doi:10.1039/b804854a

9. Roach, P.; Shirtcliffe, N. J.; Newton, M. I. Soft Matter 2008, 4, 224-240. doi:10.1039/b712575p

10. Nishino, T.; Meguro, M.; Nakamae, K.; Matsushita, M.; Ueda, Y. Langmuir 1999, 15, 4321-4323. doi:10.1021/la981727s

11. Koch, K.; Barthlott, W. Philos. Trans. R. Soc., A 2009, 367, 1487-1509. doi:10.1098/rsta.2009.0022

12. Wenzel, R. N. Ind. Eng. Chem. 1936, 28, 988-994. doi:10.1021/ie50320a024

13. Cassie, A. B. D.; Baxter, S. Trans. Faraday Soc. 1944, 40, 546-551. doi:10.1039/tf9444000546

14. Feng, L.; Zhang, Y.; Xi, J.; Zhu, Y.; Wang, N.; Xia, F.; Jiang, L. Langmuir 2008, 24, 4114-4119. doi:10.1021/la703821h

15. Bhushan, B.; Her, E. K. Langmuir 2010, 26, 8207-8217. doi:10.1021/la904585j

16. Lafuma, A.; Quéré, D. Nat. Mater. 2003, 2, 457-460. doi:10.1038/nmat924

17. Bormashenko, E. Philos. Trans. R. Soc., A 2010, 368, 4695-4711. doi:10.1098/rsta.2010.0121

18. Bormashenko, E. Y. Wetting of real surfaces; Walter de Gruyter, 2013. doi:10.1515/9783110258790

19. Whyman, G.; Bormashenko, E. Langmuir 2011, 27, 8171-8176. doi:10.1021/la2011869
20. Koch, K.; Bohn, H. F.; Barthlott, W. Langmuir 2009, 25, 14116-14120. doi:10.1021/la9017322

21. Mayser, M. J.; Barthlott, W. Integr. Comp. Biol. 2014, in press. doi:10.1093/icb/icu072

22. Balasubramanian, A. K.; Miller, A. C.; Rediniotis, O. K. AIAA J. 2004, 42, 411-414. doi:10.2514/1.9104

23. Fukagata, K.; Kasagi, N.; Koumoutsakos, P. Phys. Fluids 2006, 18, 051703. doi:10.1063/1.2205307

24. Henoch, C.; Krupenkin, T. N.; Kolodner, P.; Taylor, J. A.; Hodes, M. S.; Lyons, A. M.; Peguero, C.; Breuer, K. Turbulent drag reduction using superhydrophobic surfaces. In 3rd AIAA Flow Control Conference, San Francisco, CA, June 5-8, 2006; Breuer, K., Ed.; American Institute of Aeronautics and Astronautics: Reston, VA, 2006; p 3192. doi:10.2514/6.2006-3192

25. McHale, G.; Newton, M. I.; Shirtcliffe, N. J. Soft Matter 2010, 6, 714-719. doi:10.1039/b917861a

26. Busse, A.; Sandham, N. D.; McHale, G.; Newton, M. I. J. Fluid Mech. 2013, 727, 488-508. doi:10.1017/jfm.2013.284

27. Melskotte, J.-E.; Brede, M.; Wolter, A.; Barthlott, W.; Leder, A. Schleppversuche an künstlichen, Luft haltenden Oberflächen zur Reibungsreduktion am Schiff. 21. GALA-Fachtagung "Lasermethoden in der Strömungsmeßtechnik" 2013, München, Germany; Kähler, C. J.; Hain, R.; Cierpka, C.; Ruck, B.; Leder, A.; Dopheide, D., Eds.; München, Germany, 2013.

28. Corbett, J. J.; Koehler, H. W. J. Geophys. Res. 2003, 108. doi:10.1029/2002JD002898

29. Eyring, V.; Isaksen, I. S. A.; Berntsen, T.; Collins, W. J.; Corbett, J. J.; Endresen, O.; Grainger, R. G.; Moldanova, J.; Schlager, H.; Stevenson, D. S. Atmos. Environ. 2010, 44, 4735-4771. doi:10.1016/j.atmosenv.2009.04.059

30. Cerman, Z.; Striffler, B. F.; Barthlott, W. Dry in the water: the superhydrophobic water fern Salvinia - a model for biomimetic surfaces. In Functional Surfaces in Biology: little structures; Gorb, S. N., Ed.; Springer: Berlin, Heidelberg, 2009; Vol. 1, pp 97-111. doi:10.1007/978-1-4020-6697-9_7

31. Balmert, A.; Bohn, H. F.; Ditsche-Kuru, P.; Barthlott, W. J. Morphol. 2011, 272, 442-451. doi:10.1002/jmor.10921

32. Ditsche-Kuru, P.; Schneider, E. S.; Melskotte, J.-E.; Brede, M.; Leder, A.; Barthlott, W. Beilstein J. Nanotechnol. 2011, 2, 137-144. doi:10.3762/bjnano.2.17

33. Barthlott, W.; Wiersch, S.; Čolić, Z.; Koch, K. Botany 2009, 87, 830-836. doi:10.1139/B09-048

34. Barthlott, W.; Riede, K.; Wolter, M. Amazoniana 1994, 13, 47-58.

35. Barthlott, W.; Schimmel, T.; Wiersch, S.; Koch, K.; Brede, M.; Barczewski, M.; Walheim, S.; Weis, A.; Kaltenmaier, A.; Leder, A.; Bohn, H. F. Adv. Mater. 2010, 22, 2325-2328. doi:10.1002/adma.200904411

36. Bhushan, B. Savlinia Effect. In Biomimetics - Bioinspired Hierarchical-Structured Surfaces for Green Science and Technology; Bhushan, B., Ed.; Springer-Verlag: Berlin Heidelberg, 2012; pp 177-186.

37. Konrad, W.; Apeltauer, C.; Frauendiener, J.; Barthlott, W.; Roth-Nebelsick, A. J. Bionic Eng. 2009, 6, 350-356. doi:10.1016/S1672-6529(08)60133-X

38. Koch, K.; Schulte, A. J.; Fischer, A.; Gorb, S. N.; Barthlott, W. Bioinspiration Biomimetics 2008, 3, 046002. doi:10.1088/1748-3182/3/4/046002 


\section{License and Terms}

This is an Open Access article under the terms of the Creative Commons Attribution License

(http://creativecommons.org/licenses/by/2.0), which permits unrestricted use, distribution, and reproduction in any medium, provided the original work is properly cited.

The license is subject to the Beilstein Journal of Nanotechnology terms and conditions:

(http://www.beilstein-journals.org/bjnano)

The definitive version of this article is the electronic one which can be found at:

doi:10.3762/bjnano.5.93 